\title{
Pastiche of My Subjectivity
}

". . . the producers of culture have nowhere to turn but to the past."

F. Jameson

I celebrate my subjectivity and write myself

And what I assume I become,

For every signifier constituting me as well constitutes my other.

I free-float and produce a soul-effect,

I float and fetishize a blade of summer fescue.

My sounds, every traveling phoneme, formed from this language, this noise,

Originating in a discourse community, inflected by inflection, no origin, all origins.

I, without history, in normative physicality reenter,

Hoping to continue in this state until not.

Ideologies and hegemonies marginalized,

Temporarily, spatially, decentered, never absent,

I seek space, I announce myself,

With Late Capitalism and unchecked commodity explosiveness.

II

Televisions and CRTs are full of text, the silicon, wires jammed with electrobits,

I read the images and know them and like them,

Their spill mesmerizes me and I endorse it.

The world is not real, it does not exist outside my signification,

It is for my organs, my senses, I am scopophilia,

I will plug into the circuit, become cyborg, cybourgeois,

I am mad for it to be in contact with me.

The vibrations of my own utterance

Echoes, ripples, buzzed whispers, clouded meanings, ego, other, mine, mine, mine.

My dreams, my stream of thoughts coursing through my brain, the passing of light and electrons through the rods and cones, my iris dilating,

The color green: envy, sea, money, spring, greenness,

The image of my sound oscillating like jump ropes through the wind, wave, particle, shock, compression, 
A few light kisses, oral gratification - the sound of one lip smacking, The play of words jumping rope, hushed screams,

The delight of loneliness - shattered-reconstructed of many, the loss of loneliness-nostalgia without memory.

The momentary illusion of organization, the uncanny, familiar images: the moon, circle, male, full stop, death, life, reflection, specularity, concave, the moon.

Have you a working myth of order? Are your categories meaningful?

Have you practiced decoding?

Have you felt so proud to get at the meaning of advertising?

Slip on a signifier with me yesterday and tomorrow and you will be confused, ever flickering,

You shall possess human agency (there are many subversive subject positions).

You shall always take things eighth, tenth, thousandth hand, the simulacrum, the xerox with no original,

You shall distort, interfere, effect with your presence/absence,

You shall listen to all sides and filter them from yourself.

University of Minnesota, Twin Cities

Paul Baepler 